\title{
LARGE STRATOSPHERIC SUDDEN WARMING IN ANTARCTIC LATE WINTER AND SHALLOW OZONE HOLE IN 1988 (ABSTRACT)
}

\author{
Hiroshi Kanzawa and Sadao Kawaguch \\ National Institute of Polar Research, 9-10, Kaga 1-chome, \\ Itabashi-ku, Tokyo 173
}

Observational data of ozone at Syowa Station $\left(69^{\circ} \mathrm{S}, 40^{\circ} \mathrm{E}\right)$ was mainly used in this study. There occurred a large stratospheric sudden warming in the southern hemisphere in late winter of 1988 which competes in suddenness and size with major mid-winter warmings in the northern hemisphere. Associated with the dynamical phenomenon of the sudden warming, total ozone increased over the eastern hemispheric part of Antarctica. The sudden warming as well as other warmings which followed it made the 1988 Antarctic ozone hole shallow in depth and small in area.

For details, the reader may refer to the full paper of this work (H. Kanzawa and S. KawAGUCHI: Geophys. Res. Lett., 17, 77, 1990).

(Received March 21, 1990)

\section{RECENT INTERANNUAL CHANGES OF STRATOSPHERIC TEMPERATURES (ABSTRACT)}

\author{
Toshihiko Hirooka ${ }^{1}$ and Kohji KaWAHIRA² \\ 'Meteorological College, 4-81, Asahi-cho 7-chome, Kashiwa 277 \\ ${ }^{2}$ Toyama National College of Technology, 13, Hongo-cho, Toyama 939
}

Recent interannual changes of zonal mean temperatures of mid and high latitudes in the lower and middle stratosphere are investigated for the period from 1980 to 1986 with the use of TIROS$\mathrm{N}$ and NOAA series satellite data $(50-10 \mathrm{mb})$ and NMC data $(300-50 \mathrm{mb})$.

The zonal mean temperatures of the Southern Hemisphere lower stratosphere $(300-50 \mathrm{mb}$ layer) decrease in all seasons as already shown (K. KawaHiRa and T. HiRooKa: Geophys. Res. Lett., 16, 41, 1989). Those of the Northern Hemisphere lower stratosphere also decrease in all seasons, although it is relatively difficult to discern such cooling in winter because of the irregular occurrence of stratospheric sudden warmings; in that case, the temperatures increase in higher latitudes while decreasing in lower latitudes.

On the other hand, as for the middle stratosphere (50-10 mb layer), an increase of zonal mean temperature can be seen only in the Southern Hemisphere winter. In other seasons of the middle stratosphere of both hemispheres, significant interannual temperature changes cannot be seen from the current short analysis period. These trends found in the temperature field seem to be associated with interannual changes of general circulation of the stratosphere. Therefore, further observations of other dynamical quantities are needed in order to thoroughly understand the recent changes of stratospheric temperatures. 